\title{
MODELLING OF URBAN GROWTH WITH LAND CHANGE MODELER IN OTUKPO METROPOLIS OF BENUE STATE, NIGERIA
}

\author{
JANDE, Joseph Asen \\ Department of Social and Environmental \\ Forestry, Federal University of \\ Agriculture Makurdi, Benue State, \\ Nigeria
}

\author{
NSOFOR, Godwin Nnaemeka \\ Department of Geography, Federal \\ University of Technology, Minna, \\ Niger State, Nigeria
}

\author{
ABDULKADIR, Ashetu \\ Department of Geography, Federal \\ University of Technology, Minna, \\ Niger State, Nigeria
}

\begin{abstract}
The study was aimed at modelling urban growth in Otukpo area of Benue State The study covered a period of 30 years; from 1987 to 2017, and the major transitions to urban were modelled to predict the future scenarios in 2030. Three Landsat satellite images of 1987, 2007 and 2017 were classified using maximum likelihood classifier in Idrisi Selva to detect the land cover changes and a classification accuracy of $84.85 \%, 85.59 \%$ and $86.44 \%$ for 1987,2007 and 2017 maps respectively was achieved. The result of the classification revealed that between 1987 and 2017, urban area gained 12224ha $(376.01 \%)$ with an annual rate of change of $12.53 \%$ while forest lost16493ha $(-49.63 \%)$ at the rate of $-1.65 \%$ per year. Physical and proximity factors were identified as major factors driving urban growth in the area. It was found that evidence likelihood of transition, population density the distance from railway and elevation were the most important factors shaping urban growth in the area. Thereafter, a Multilayer Perceptron Markov (MLPMarkov) model was used to model transition potentials of various LULC types to predict future changes. The models had a reliability of $81.7 \%$ after validation. The results of the prediction show that Otukpo will experience increase in urban area from $11.59 \%$ to $12.6 \%$ and forest will decline from $12.54 \%$ to $10.98 \%$. It reveals that, Otukpo will grow at the rate of $1.01 \%$. Analysis of the prediction revealed that the rate of urban growth will continue and would certainly threaten other land covers in the area.
\end{abstract}

Keywords - Urban growth Otukpo, Landsat satellite images, maximum likelihood classifier, Idrisi Selva, evidence likelihood of transition, Multilayer Perceptron Markov

\section{INTRODUCTION}

It has been observed over the years that urban areas are the most areas prone to changes on the surface of the Earth. In most cases, urban growth is experienced towards the boundary between urban and rural areas where the density of settlements is less. Over the past few years, there has been a lot of growth in urban areas the world over, and population increase has been the key factor responsible for this. Over half of population increase of the world between now and 2050 is predicted to occur in Africa with Nigeria inclusive. Before now a greater percentage of the world population was in the rural areas but today a greater percentage now lives in urban areas. The United Nations World Urbanisation Prospects(UN, 2014) confirms this when it was asserted that $54 \%$ of the population of the world resides in urban areas as at 2014. The ever increasing urban growth is triggering environmental problems and risks associated with urban dwellers where management is necessary to ensure quality of life and sustainability. (Debnath and Amin, 2015)

As noted by Ujoh, et al. (2011) several urban growth studies in Nigeria tend to focus on a specific city as a case study, from which they have derived generalisations of transformations occurring at the national level. Most of these cities are state capital but little has been done on investigating urban growth pattern in smaller urban centres like Local Government headquarters and unravel their pattern.

Urban expansion driven by urban population growth has been marked with widespread consequences, and is expected to continue and indeed likely go through a phase of strong increase in Nigeria. Urbanisation (as urban population growth) has thus had profound consequences for the physical configuration of urban settlements in Nigeria. Bloch et al. (2015) in their work observed that present-day urban structures are undergoing transformation as new areas appear, typically on urban peripheries or fringes, and established areas adjust to accommodate increases in urban populations. Rapid rise in urban population has caused serious environmental damages with problems such as increasing slums, decrease in standard of living, The detailed characteristics of modern-day urban expansion therefore require investigation, not least to inform urban policy, strategic spatial planning and the programming required to design and resource the provision of infrastructure and services for a burgeoning urban population. Otukpo is one of the ancient towns in Otukpo and it has undergone series of phases in its growth and there is need to 


\section{International Journal of Engineering Applied Sciences and Technology, 2020 \\ Vol. 4, Issue 9, ISSN No. 2455-2143, Pages 26-40 \\ Published Online January 2020 in IJEAST (http://www.ijeast.com)}

study it with a view to predicting the future patterns to aid planning.

A wide range of models of urban growth had been developed to help in urban growth analysis and prediction of urban growth patterns within the functioning of earth system. Jain et al. (2017) concluded that the analysis of land use and land cover (LULC) change helps to determine to what extent the area would be changed in near future

This is aimed at Modelling of Urban growth with Land Change Modeler in Otukpo area of Benue State, Nigeria with these specific objectives:

i. Map the types and extent of LULC classes in Otukpo area of Benue State.

ii. Analyse the trend and rate of LULC changes between 1987 and 2017.

iii. Identify the drivers and their contributions to urban growth in the area.

iv. Model and predict the pattern of urban growth in Otukpo area for 2030

\section{MATERIAL AND METHODS}

\section{Study Area}

Otukpo lies between longitude $7^{\circ} 50^{\prime}$ and $8^{\circ} 20^{\prime}$ East of the Greenwich Meridian and Latitude $6^{\circ} 50^{\prime}$ and $7^{\circ} 40^{\prime}$ North of the Equator as shown in Figure 1.

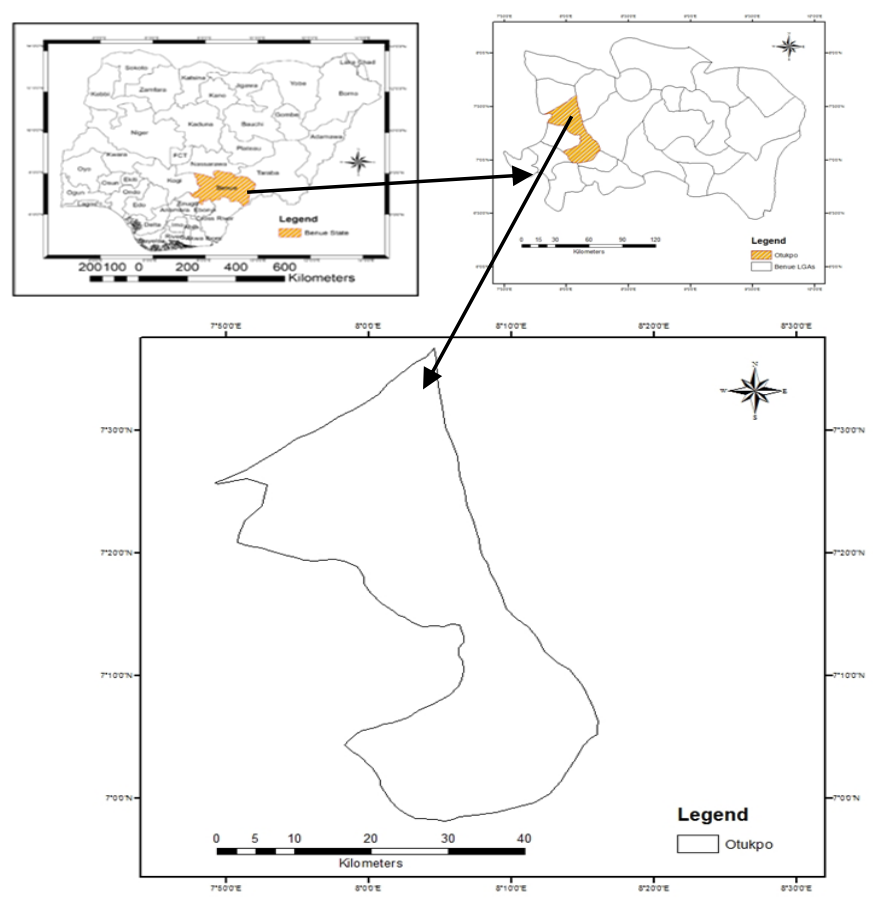

Figure 1: The Study Area

It has common boundary with Okpokwu, Ado and Obi LGAs in the south, Apa and Gwer West LGAs in the north, Gwer
East LGA in the east, and Ohimini LGA and Kogi State in the west. (BNSG, 2017)

The drainage system of the area is influenced by factors such as relief, climate, rock structure and human activities in the area. The drainage system in the area is characterised by the presence of smaller streams that serve as tributaries to River Niger. Several other streams do not empty their waters into river Niger. These rivers and streams provide extensive alluvial floodplains that are utilised extensively for irrigation farming. The local government is situated in the tropical climate region and has two different seasons, the rainy (wet) season and the dry season (Abah, 2014).The wet season commences in the month of April and lasts till October having a break in August, while the dry season starts from November and ends in March. The yearly rainfall is between $15 \mathrm{~cm}$ and $18 \mathrm{~cm}$. Temperatures varies between $23^{\circ} \mathrm{C}-38^{\circ} \mathrm{C}$ for most of the year. The mean monthly values of rainfall in the area range from $0.77 \mathrm{~cm}$ to $22.75 \mathrm{~cm}$. The harmattan winds usually brings a cooling effect particularly from November to February and it is linked with seasonal dust haze coming from the prevailing dry NE trade winds from the Sahara Desert (BNSG, 2017).

The vegetation is mainly the Guinea savannah with trees and tall grasses mixed together having average height. The natural vegetation consists of woodland and tall grass. The guinea savannah has isolated forests, patches of woodland, scrubs and shrubs in addition to tall grasses(Abah, 2014). Halima and Edoja, (2016) and Hula, (2014)observed that the vegetation of the area was hitherto covered by forest but due to uncontrolled and continuous clearing of the vegetation for agricultural activities together with other anthropogenic activities such as burning of the bushes, grazing and hunting among others, have to a large extent, impacted on the original forests. The original forest vegetation is now reduced to secondary forest and savannah vegetation.

Continuous clearance of the forest vegetation has given rise to the emergence of secondary vegetation at various stages of growth. The grasses grow very tall and are coarse when matured. There are pockets of scattered trees that are of economic benefits and they include mango, shea butter, locust bean, African iron, Isoberlinia, cashew, Danielliaoliveri, Gmelina arborea, oil palm, etc. These trees produce products that serve as raw material for some small-scale industries.

The appearance of the vegetation cover varies according to the season. During rainy season, the vegetation becomes very fresh and greenish but wither and die away in the dry season. Some trees are deciduous shading their leaves during the dry season but regain their leaves with the onset of the next rainy season. The plants have adaptive features to enable them overcome the drought conditions by developing long taproots, leathery leaves and succulent stems(Hula, 2014).

Otukpo has a population of 266,411 according to the National population census of 2006 and is placed third in Otukpo as the 


\section{International Journal of Engineering Applied Sciences and Technology, 2020 \\ Vol. 4, Issue 9, ISSN No. 2455-2143, Pages 26-40 \\ Published Online January 2020 in IJEAST (http://www.ijeast.com)}

most populated local government after Gboko and Makurdi.,(NBS, 2012). The area is mostly rural, where settlements are dispersed in small homesteads with the population mostly farmers. Otukpo is the traditional seat of power of Idoma. The people of the area are mainly farmers. Over $80 \%$ of the total population is dependent on farming for their living taking advantage of the fertile rich alluvial soils. The area is blessed with agricultural products such as yam, cassava, rice, soya beans, millet, potatoes, guinea corn, groundnuts, maize and benniseed.(Otukpo Government, 2017).

\section{Data requirement and collection}

The data used for this study was derived mainly from secondary sources such as Satellite Remote Sensing imageries, Digital Elevation Model (DEM), Population data, Road network, Rail network and drainage network characteristics. This was augmented with primary data such as personal observation, taking of locational points using handheld Global Positioning System (GPS). The GPS was also used for ground truthing during image classification.

\section{Satellite Remote Sensing Imageries}

Satellite imageries used included Landsat TM (1987); Landsat ETM+ (2007); and Operational Land Imager (OLI) (2017). The Landsat imagery dataset was sourced from the Earthexplorer platform from United States Geological Surveys (USGS), Global Land Cover Facility (GLCF) and GloVis. Changes in land cover were measured using time series of remotely sensed data (Landsat TM, ETM and OLI). Table. 1 gives a summary of the image characteristics for the dataset used. Dry season images of the three data sets were acquired from January to March in order to reduce the effects of clouds that are prevalent during the rainy season. Because the images are from the same season and comparable climatic conditions, it enhanced the classification as the spectral reflection of most features are easily comparable across the different images. In addition, high resolution Google earth images were used to aid in classification.

Table 1: Specifications of Satellite Imageries Used

\begin{tabular}{lcccccc}
\hline Satellite & $\begin{array}{c}\text { Path/ } \\
\text { Row }\end{array}$ & Sensor & $\begin{array}{c}\text { No of } \\
\text { Bands }\end{array}$ & $\begin{array}{c}\text { Bands } \\
\text { used }\end{array}$ & $\begin{array}{c}\text { Date } \\
\text { Acquired }\end{array}$ & $\begin{array}{c}\text { Spatial } \\
\text { Resolution }\end{array}$ \\
\hline Landsat & $188 / 55$ & TM & 7 & $\begin{array}{c}\text { NIR, R, } \\
\text { G }(4,3,2)\end{array}$ & $29 / 01 / 1987$ & $30 \mathrm{~m}$ \\
& & & & & \\
Landsat & $188 / 55$ & ETM+ & 8 & NIR, R, & $21 / 12 / 2007$ & $30 \mathrm{~m}$ \\
& & & & G $(4,3,2)$ & & \\
Landsat & $188 / 55$ & OLI & 11 & NIR, R, & $16 / 02 / 2017$ & $30 \mathrm{~m}$ \\
& & & & G $(5,4,3)$ & & $30 \mathrm{~m}$ \\
ASTER & - & Radio & 1 & - & 2011 & \\
GDEM $*$ & & meter & & & & \\
\hline
\end{tabular}

$\mathrm{TM}=$ Thematic Mapper, ETM+= Enhanced Thematic Mapper Plus, OLI = Operational Land Imager:

\section{Digital Elevation Model (DEM)}

The Digital Elevation Model (DEM) data used were the Advanced Spaceborne Thermal Emission and Reflection Radiometer (ASTER) DEM for the year 2014, (Table 1). The data is a raster data format, having spatial resolution of 30 meters and a scene coverage of $1^{\circ} \times 1^{\circ}$ (approximately $111 \mathrm{~km}$ $\mathrm{x} 111 \mathrm{~km})$. The data were downloaded using the Earthexplorer online platform from United States Geological Surveys (USGS).A subset of the area covering the study area was done. The DEM was used for the determination of slope and elevations of points which affect the cost of construction. Higher slopes and marshy areas attract higher cost of construction as opposed to plain and gentle slopes.

\section{Other Ancillary Data}

Population data- were sourced from the National Population Commission. The population of the 23 local government areas was mapped to produce the population density of the state.

Transportation network- Major roads and rail network were mapped from Google Earth in order to have an up-to-date database of the transportation network in the state.

Drainage network characteristics- The major water bodies in the state (rivers and lakes) were mapped from Google Earth to ensure higher accuracy.

\section{Tools and materials used.}

The tools used for carrying out the research were;

i. ArcGIS 10.2 used for pre-processing of images and vector data.

ii. ERDAS Imagine 2014, used for classification and accuracy assessment of classification

iii. Idrisi Selva, used for change detection and modelling.

iv. Google Earth Image, used for delineation and updating of transportation and drainage maps. It was also used in preparing point data files for modelling.

v. Global Positioning System-This was used for classification and data validation

\section{Mapping the types and extent of LULC cover classes in Otukpo}

This objective one was achieved through the examination of Landsat TM of 1987, Landsat ETM+ of 2007 and Landsat OLI of 2017 images acquired and their subsequent classification. In order to map the types and extent of LULC classes in Otukpo, the data were subjected to some processing and analytical procedures which are outlined here.

\section{Data Pre-processing}

Landsat TM, ETM and OLI were pre-processed, so that inherent errors and formatting that are required for further 


\section{International Journal of Engineering Applied Sciences and Technology, 2020 \\ Vol. 4, Issue 9, ISSN No. 2455-2143, Pages 26-40 \\ Published Online January 2020 in IJEAST (http://www.ijeast.com)}

direct processing of the data were taken care of. The downloaded Landsat images were in separate bands and need to be layer stacked. This is a process whereby different bands of an image are joined together to form a single multispectral image. These individual bands were then stacked sequentially from 1 to 7 using ERDAS Imagine 2014. The three (3) satellite imageries, Landsat TM (1987); Landsat ETM+ (2007); and Landsat OLI (2017) were corrected radiometrically through haze removal operations, so that radiometric errors added to data, due to atmospheric scattering were corrected, using the ERDAS Imagine 2014 image processing software.

Focal analysis module in ERDAS 2014 was used in removing scan lines on images especially the 2007 Landsat image. Geometric correction refers to the process of co-registration of the satellite images, so that the images could overlap in the best possible way. This function was achieved in IDRISI through the RESAMPLE module. This is very essential due to the fact that some of the essential methods are based on the comparison of the two images from different time periods. Although most of Landsat images have been already georeferenced, images with a lot of cloud cover could have low geometric accuracy, and therefore required to be georeferenced.

In order to obtain images that are cloud free, mosaicking of two or more images of the same area was performed in order to replace pixels affected by clouds with cloud free pixels from another image. In order to do this, accurate geometric registration among images was done. For radiometric compatibility, it is imperative that mosaic is done between images of the same season. In effect, the appearance of vegetation varies greatly during the year; therefore, all the images need to be acquired in less than one month, or at least be acquired exactly in the same month of different years (Congedo and Munafò, 2012). The area of study covers more than a single scene of Landsat. As a result, several scenes were acquired as shown in Table 3.1. The Digital Elevation Model (DEM) data were used to produce elevation and slope characteristics of the area.

\section{Image rectification}

This operation was carried out through clipping of the study area using the scenes. The shapefile of Otukpo was used to clip from the larger scenes. The technique used was the subset method in ERDAS 2014 and the desired shapefile of Otukpo was used as the Area of Interest (AOI). The choice of this method was based on its simplicity of use and its higher accuracy. This is because the entire scene is larger than the Area of interest (AOI) and it helps in defining precisely the study area.

\section{Image classification:}

A per-pixel image classification method for ground cover analysis was used through a supervised classification algorithm which is a procedure for categorizing spectrally similar areas on an image by identifying "training" sites of known targets and then generalizing those spectral signatures to other areas of targets that are unknown (Mather and Koch, 2011). It is a process of using samples whose identity is known to categorize samples whose identity is unknown. A Maximum Likelihood algorithm of supervised classification was adopted because of the author's familiarity with the terrain. This method was chosen because it is easier to accomplish and more so, the large volume of images to be interpreted could not warrant the use of visual on-screen interpretations. The visual method depends largely on the skill and familiarity of the interpreter and is therefore prone to much error if the interpreter is not well experienced. The identification of training sites used was based on spontaneous recognition and logical inference both of which are products of visual interpretation. (Congedo and Munafò, 2012).

Huang et al. (2009) asserted that the Maximum Likelihood is one of the most commonly used supervised classifiers, which uses the Gaussian threshold stored in each class signature to assign every pixel a class. Maximum Likelihood classification assumes that the probability distributions for the classes follow the normal distribution model(Richards and Jia, 2006). The discriminant function, as described by Richards and Jia, (2006), is:

$\mathrm{g}_{\mathrm{i}}(\mathrm{x})=\ln \mathrm{p}\left(\omega_{\mathrm{i}}\right)-1 / 2 \ln \left|\Sigma_{\mathrm{i}}\right|-1 / 2\left(\mathrm{x}-\mathrm{m}_{\mathrm{i}}\right)^{\mathrm{t}} \Sigma_{\mathrm{i}}^{-1}\left(\mathrm{x}-\mathrm{m}_{\mathrm{i}}\right)$ (1)

where: $\omega_{i}=$ class $($ where $\mathrm{i}=1, \ldots \mathrm{M}$ and $\mathrm{M}$ is the total number of classes)

$\mathrm{x}=$ pixel vector in $\mathrm{n}$-dimension where $\mathrm{n}$ is the number of bands

$p\left(\omega_{i}\right)=$ probability that the correct class is $\omega_{i}$ occurs in the image and is assumed the same for all classes

$\left|\Sigma_{\mathrm{i}}\right|=$ determinant of the covariance matrix of the data in class $\omega_{\mathrm{i}}$

$\Sigma_{\mathrm{i}}^{-1}=$ inverse of the covariance matrix and $\mathrm{m}_{\mathrm{i}}=$ mean vector The Maximum Likelihood method was used, because it is one of the best classification methods which assigns pixels to the class with the largest probability to determine class membership of a particular pixel. In choosing training sites, colour composite images formed by the combination of three individual monochrome images, which highlight certain surfaces, and help photo-interpretation were viewed. Each band is assigned to a given colour: Red, Green and Blue (RGB)(NASA, 2011). In order to ascertain the areal extent and rate of change in the LULC of Otukpo, the following variables were computed.

Total area $\left(\mathrm{T}_{\mathrm{a}}\right)$, Changed area $\left(\mathrm{C}_{\mathrm{a}}\right)$, Change extent $\left(\mathrm{C}_{\mathrm{e}}\right)$ and Annual rate of change $\left(\mathrm{C}_{\mathrm{r}}\right)$ These variables can be described by the following formula as given by: Yesserie (2009)

$$
\mathrm{C}_{\mathrm{a}}=\mathrm{T}_{\mathrm{a}}\left(\mathrm{t}_{2}\right)-\mathrm{T}_{\mathrm{a}}\left(\mathrm{t}_{1}\right)
$$

$$
\mathrm{C}_{\mathrm{e}}=\mathrm{C}_{\mathrm{a}} / \mathrm{T}_{\mathrm{a}}\left(\mathrm{t}_{1}\right) \text {; }
$$

Where $t_{1}$ and $t_{2}$ are the beginning and ending times of the land use and land cover studies conducted. 
Table 2: Classification scheme adopted.

\begin{tabular}{|c|c|c|}
\hline $\mathrm{S} / \mathrm{N}$ & Class & Description \\
\hline 1 & $\begin{array}{l}\text { River/ water } \\
\text { bodies }\end{array}$ & $\begin{array}{l}\text { Open water features including lakes, } \\
\text { rivers, streams,ponds and reservoirs. }\end{array}$ \\
\hline 2 & $\begin{array}{l}\text { Built- } \\
\text { up/Urban } \\
\text { Areas }\end{array}$ & $\begin{array}{l}\text { Urban and rural built-up including } \\
\text { homestead area such as residential, } \\
\text { commercial, industrial areas, villages, } \\
\text { settlements, road network, pavements, } \\
\text { and man-made structures. }\end{array}$ \\
\hline 3 & Grassland & $\begin{array}{l}\text { Areas dominated by grasses including } \\
\text { vegetated sandbars and grazing areas/ }\end{array}$ \\
\hline 4 & Bare surface & $\begin{array}{l}\text { Fallow land, earth and exposed river } \\
\text { sand land in-fillings, construction sites, } \\
\text { excavation sites, open space and bare } \\
\text { soils. }\end{array}$ \\
\hline 5 & Forest & $\begin{array}{l}\text { Trees, natural vegetation, mixed forest, } \\
\text { gardens, parks and playgrounds, } \\
\text { grassland, vegetated lands. }\end{array}$ \\
\hline 6 & Farmlands & $\begin{array}{l}\text { Areas consisting of cultivated lands } \\
\text { used for the production of annual } \\
\text { crops, perennial woody crops. } \\
\text { agricultural lands, and crop fields. }\end{array}$ \\
\hline
\end{tabular}

Source: Modified from Anderson et al.(1976)

\section{Fieldwork and Ground-truthing}

Fieldwork was done so as to collect geographical data to map land cover and for accuracy assessment of the land cover classification. Ground-truth data were also collected on spatial features from the study area, such as spatial location, land cover and land use, road network with the aid of a GPS. Ground truthing enabled the collection of inference data and to increase ones' knowledge of land cover conditions. It also enables familiarity of features as they appear on the satellite image on the computer screen, for verification and validation of the interpreted results. The process of identifying and transferring ground points onto the screen was done using the GPS. Each LULC class was physically identified in the field and the position of the area recorded using GPS which was later transferred to the image whereby it was easier to identify the appearance of such land uses and land cover on the screen. Inaccessible areas were complimented with the use of Google earth images. In summary, both visual interpretation and digital image classification methods were employed in data interpretation.

\section{Sampling Technique}

The sampling technique adopted in selecting control points for accuracy assessment was the stratified random sampling. According to Olofsson et al. (2014), there are two primary purposes to implement stratification in the accuracy assessment: 1) when the strata are of interest for reporting results and 2) when there is the need to improve the precision of the accuracy and area estimates. It avails one the opportunity of selecting control points within the different land use and land cover classes (strata) to be used for accuracy assessment. Each of the land use and land cover classes had control points proportional to the size of the area covered.

\section{Accuracy Assessment}

The accuracy of satellite image classification could be inhibited by the resolution of images used and dearth of fine details as well as unavoidable generalization impact and therefore, errors are always expected. This is why, to ensure wise utilization of the produced LULC maps and their associated statistical results, the errors and accuracy of the analysed outputs should be quantitatively explained (Siddhartho, 2013). Accuracy assessment is a process whereby the final product of classification is compared with ground truth or reliable sources so as to assess the extent of agreement or disagreement. This study adopted the Error Matrix approach as used by Friehat et al. (2015) to assess the accuracy of the classification.

Accuracy assessments of the classified maps (1987, 2007 and 2017) were done using the error matrix (ERRMAT in Idrisi Selva). The error matrix assesses accuracy using four parameters which include overall accuracy, user's accuracy, producer's accuracy and the Kappa Index of agreement (KIA). The overall accuracy specifies the total pixels correctly classified and is derived by dividing the total number of pixels correctly classified by the total number of pixels in the error matrix. The producer's accuracy defines the probability of a reference pixel being correctly classified. It represents the error of omission. The number of samples correctly classified for a given column is divided by the total for that column (Pedro, 2015). The user's accuracy on the other hand defines the probability that a pixel classified on a map actually represents that category on the ground. User's accuracy represents the error of commission. This can be calculated by dividing the number of samples correctly classified for a given row by the total of the row (Pedro, 2015). On the other, the Kappa index measures the agreement between classification map and reference data (Congalton and Green, 2008). All accuracy parameters have index values between 0 and 1 , where 0 symbolizes poor and 1 , strong classification accuracy/agreement.

The Kappa statistics formula developed by Cohen Kappa in 1960 and modified by Jenness and Wynne (2007) was adopted for calculating Kappa statistic. It has the advantage of correcting for chance agreements between the observed and predicted values.

$k=\frac{N \sum_{i=1}^{n} m_{i, i}-\sum_{i=1}^{n}\left(G_{i} C_{i}\right)}{N^{2}-\sum_{i=1}^{n}\left(G_{i} C_{i}\right)}$

Where $: i$ is the class number

$N$ is the total number of classified pixels that are being compared to ground truth 


\section{International Journal of Engineering Applied Sciences and Technology, 2020 \\ Vol. 4, Issue 9, ISSN No. 2455-2143, Pages 26-40 \\ Published Online January 2020 in IJEAST (http://www.ijeast.com)}

$m i, i$ is the number of pixels belonging to the ground truth class $\mathrm{i}$, that have also been classified with a class $\mathrm{i}$ (that is, values found along the diagonal of the confusion matrix)

$\mathrm{Ci}$ is the total number of classified pixels belonging to class $i$ $G i$ is the total number of ground truth pixels belonging to $i$

Kappa value changes from -1 to +1 and the interpretation of the values can be determined according to these values:

$<0$ : Less than chance agreement

0.01-0.20: Slight agreement

0.21-0.40: Fair agreement

0.41-0.60: Moderate agreement

0.61-0.80: Substantial agreement

0.81-0.99: Almost perfect agreement. (Borana and Yadav, 2017).

Under ideal conditions, the accuracy of the classification ought to be assessed by overlaying an already existing LULC map. Due to absence of already existing LULC classification for Otukpo, handheld Garmin GPS receiver was used to take coordinates of selected LULC as ground control points from the field complimented with Google Earth images. The points of these reference data were determined through stratified random sampling by identifying and locating the land use classes of interest in the field and their GPS points and coordinates taken at $\pm 3 \mathrm{~m}$ accuracy and recorded as was used by Appiah (2016).

\section{ANALYSIS OF THE TREND OF LAND USE AND LAND COVER CHANGES FROM 1987- 2017}

The methodology for achieving this objective two was through the use of Change Analysis Tab in IDRISI. Here, the focus was on the spatial trend of change panel to directly detect the actual spatial pattern of each major land conversion that has taken place in Otukpo from 1987-2007, 2007-2017 and19872017. The principle under which this panel works is the polynomial order in which the spatial pattern and trend of land use and land cover between two periods is generalized. According to Eastman (2012), the spatial trend of change panel in LCM is to follow a similar pattern on Trend Surface Analysis (TSA) as in the TREND module in IDRISI. It calculates trend surface polynomial equations up to the $9^{\text {th }}$ order for spatial data sets, and then interpolates the surfaces based on those equations. The generic equation for the polynomials fitted by TREND as given by(Saifullah, Barus, \& Rustiadi, 2017) is:

$$
\mathrm{Z}=\sum_{\mathrm{i}=0}^{\mathrm{k}} \sum_{\mathrm{j}=0}^{\mathrm{i}} b \mathrm{ij} \mathrm{X}^{\mathrm{i}-\mathrm{j}} \mathrm{y}^{\mathrm{j}}
$$

Where $\mathrm{k}=$ is the maximum order to be fitted;

$b=$ coefficient of the polynomial equation;

both $i$ and $j$ are iteration variables associated with $k$, in which $i$ $=0, \ldots k$ and $j=0, \ldots i$. according to Saifullah et al. (2017)

\section{ESTABLISHING THE RATE OF RURAL-URBAN LAND CONVERSION IN OTUKPO}

This section is also part of objective two of the study. After a successful classification, the LULC classes for 1987, 2007 and 2017 were compared to determine the extent of change. The extent of change was divided by the time interval between the initial and the later date to arrive at the rate of rural- urban conversion. This operation is represented by the following equation as given by Yesserie (2009):

$$
\mathrm{C}_{\mathrm{r}}=\mathrm{C}_{\mathrm{e}} /\left(\mathrm{t}_{2}-\mathrm{t}_{1}\right) \text {; }
$$

Where $\mathrm{C}_{\mathrm{e}}=$ Change extent

$t_{1}$ and $t_{2}=$ the starting and ending times respectively of the LULC studies conducted

\section{RESULT ANALYSIS AND DISCUSSION}

\section{Classification of land use and Land cover for 1987, 2007 and 3017}

The results of classification for the land use land cover changes in 1987, 2007 and 2017 are presented using tables, charts and figures for illustration and interpretation of all LULC classes in the three periods. The results are discussed immediately as they are presented.

Extent of land use and land cover types in Otukpo

The distribution of land cover classes in Otukpo as shown in Table 3 and Figures 2, 3 and 4 reveal that Urban area occupied 3251 ha $(2,43 \%)$ in 1987 , appreciating to 8348 ha $(6.25 \%)$ in 2007 and climaxing to 15475 ha $(11.59 \%)$ in 2017.

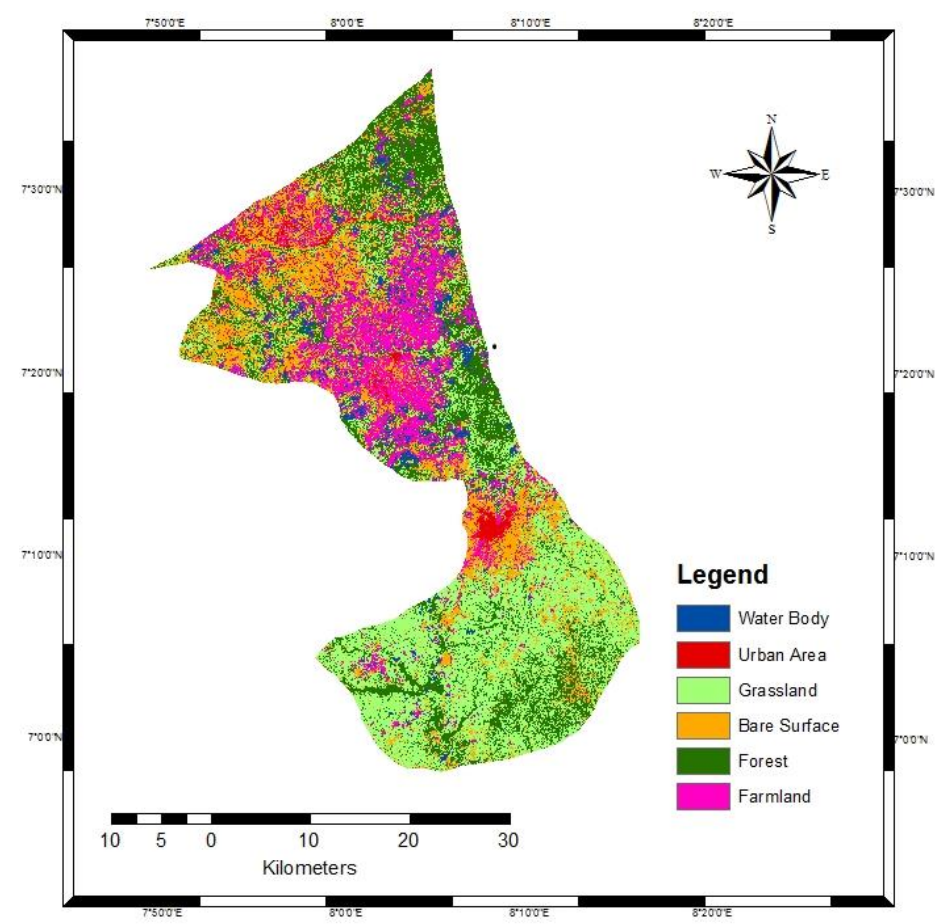

Figure 2: Land use and Land cover map of Otukpo for 1987 


\section{International Journal of Engineering Applied Sciences and Technology, 2020 \\ Vol. 4, Issue 9, ISSN No. 2455-2143, Pages 26-40 \\ Published Online January 2020 in IJEAST (http://www.ijeast.com)}

Source: Author's fieldwork, 2018

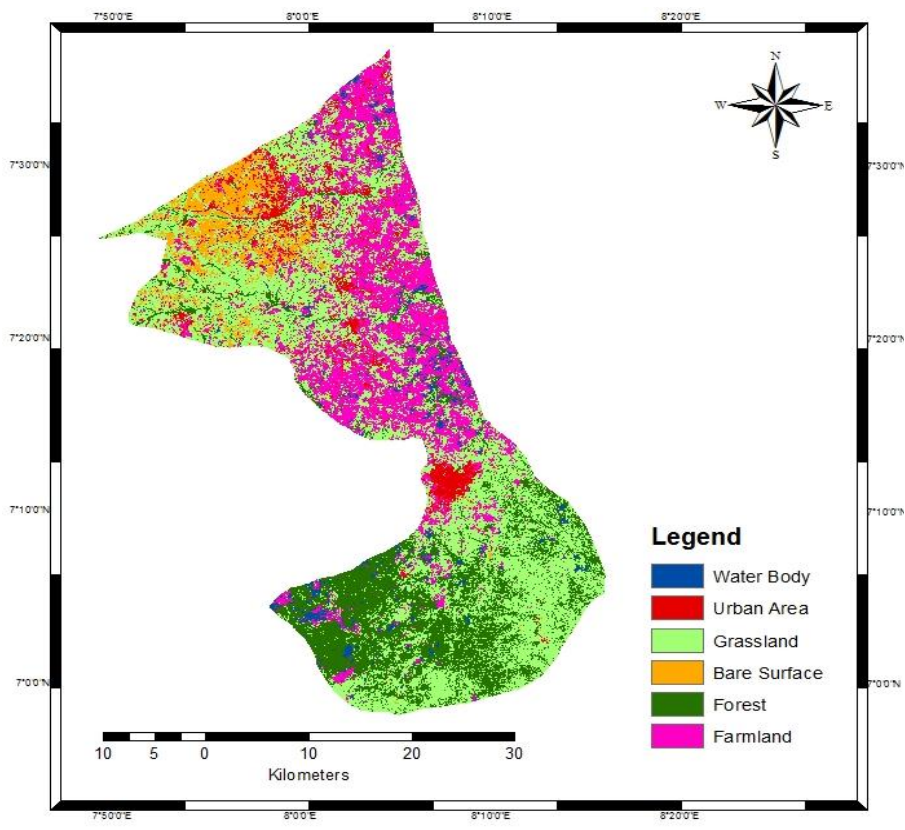

Figure 3: Land use and Land cover map of Otukpo for 2007

Source: Author's fieldwork, 2018

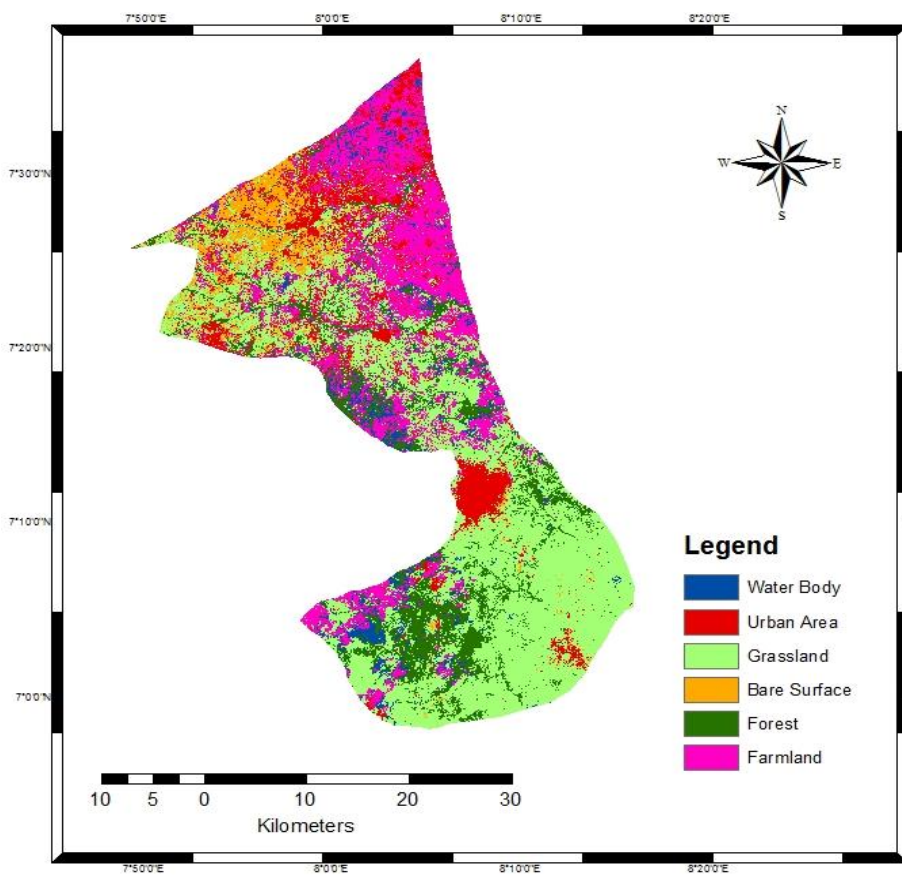

Figure 4: Land use and Land cover map of Otukpo for 2017 Source: Author's fieldwork, 2018
Forest land decreased from 33234ha (34.88\%) in 1987 to 27289ha $(20.44 \%)$ in 2007 and further declined to 16741 ha (12.54\%) in 2017. Grassland was the major land cover in Otukpo spanning an area of 42559ha (31.86\%) in 1987, expanding to $57071 \mathrm{ha}(42.75 \%)$ and 58623ha $(43.92 \%)$ in 2007 and 2017 respectively. Farmland, the second largest land cover occupied 21821ha (16.33\%) in 1987 and rose to 29778ha $(22.31 \%)$ in 2007. In 2017, however, the area devoted to farming declined to 28346 ha $(21.24 \%)$. This may be likely due to rural-urban migration by youths and the adoption of more intensive farming practices aimed at increasing output as opposed to the extensive method of expanding the area under cultivation, (Bloch, et al, 2015).

Table 3: Area Statistics of LULC in Otukpo (1987, 2007 and 2017)

\begin{tabular}{|c|c|c|c|c|c|c|}
\hline \multirow[b]{2}{*}{$\begin{array}{l}\text { Land cover } \\
\text { Class }\end{array}$} & \multicolumn{2}{|c|}{1987} & \multicolumn{2}{|c|}{2007} & \multicolumn{2}{|c|}{2017} \\
\hline & $\begin{array}{r}\text { Area } \\
(\mathbf{H a})\end{array}$ & $\begin{array}{l}\text { Area } \\
(\%)\end{array}$ & $\begin{array}{l}\text { Area } \\
\text { (Ha) }\end{array}$ & $\begin{array}{l}\text { Area } \\
(\%)\end{array}$ & $\begin{array}{r}\text { Area } \\
\text { (Ha) }\end{array}$ & $\begin{array}{l}\text { Area } \\
(\%)\end{array}$ \\
\hline \multirow[t]{2}{*}{ Water Body } & 5692 & 4.26 & 3418 & 2.56 & 6226 & 4.66 \\
\hline & & & & & & 11.5 \\
\hline \multirow[t]{2}{*}{ Urban Area } & 3251 & 2.43 & 8348 & 6.25 & 15475 & 9 \\
\hline & & 31.8 & & 42.7 & & 43.9 \\
\hline \multirow[t]{2}{*}{ Grassland } & 42559 & 6 & 57071 & 5 & 58623 & 2 \\
\hline & & 20.2 & & & & \\
\hline \multirow[t]{2}{*}{ Bare Surface } & 27034 & 4 & 7587 & 5.69 & 8080 & 6.05 \\
\hline & & 24.8 & & 20.4 & & 12.5 \\
\hline \multirow[t]{2}{*}{ Forest } & 33234 & 8 & 27289 & 4 & 16741 & 4 \\
\hline & & 16.3 & & 22.3 & & 21.2 \\
\hline \multirow[t]{2}{*}{ Farmland } & 21821 & 3 & 29778 & 1 & 28346 & 4 \\
\hline & 13349 & 100 & 13349 & & 13349 & \\
\hline Total Area & 1 & & 1 & 100 & 1 & 100 \\
\hline
\end{tabular}

Source: Author's fieldwork, 2018

\section{ACCURACY ASSESSMENT OF ClASSIFIED MAPS}

It is difficult to attain a $100 \%$ accuracy in any classification and as such there exist some standards to which each classification must attain for it to be acceptable. The accuracy of satellite image classification could be controlled by the resolution of images used and lack of fine details as well as the impact of unavoidable generalization and therefore, errors are always expected. This is why, to ensure prudent utilization of the produced LULC maps and their associated statistical results, the errors and accuracy of the analysed outputs should be quantitatively evaluated. 


\section{International Journal of Engineering Applied Sciences and Technology, 2020 \\ Vol. 4, Issue 9, ISSN No. 2455-2143, Pages 26-40 \\ Published Online January 2020 in IJEAST (http://www.ijeast.com)}

\section{Assessment of classification accuracy of land use and land cover in Otukpo.}

The result of classification accuracy for 1987, 2007 and 2017 for Otukpo showed an overall accuracy of $84.85 \%, 85.59 \%$ and $86.44 \%$ respectively (See Table 4 ). Based on the scale of assessment, it was also considered a decent overall accuracy and, therefore, usable for change detection analysis.

Table 4: Accuracy assessment result of LULC classification in Otukpo

\begin{tabular}{ccccccc}
\hline LULC & \multicolumn{2}{c}{1987} & \multicolumn{2}{c}{$\mathbf{2 0 0 7}$} & \multicolumn{2}{c}{$\mathbf{2 0 1 7}$} \\
CLASSES & PA & UA & PA & UA & PA & UA \\
& $(\boldsymbol{\%})$ & $(\boldsymbol{\%})$ & $(\boldsymbol{\%})$ & $(\boldsymbol{\%})$ & $(\boldsymbol{\%})$ & $(\boldsymbol{\%})$ \\
\hline Water Body & 86.96 & 100 & 81.48 & 91.67 & 85.71 & 94.74 \\
Urban Area & 76.47 & 100 & 85.29 & 85.29 & 79.49 & 88.57 \\
Grassland & 91.07 & 86.44 & 87.5 & 81.67 & 89.66 & 86.67 \\
Bare & 84.21 & 50 & 88 & 81.48 & 88.46 & 69.7 \\
Surface & & & & & & \\
Forest & 86.11 & 93.94 & 81.58 & 88.57 & 85.71 & 88.24 \\
Farmland & 86.21 & 89.29 & 87.5 & 87.5 & 87.72 & 90.91 \\
\hline Overall & $\mathbf{8 4 . 8 5}$ & $\mathbf{8 5 . 5 9}$ & $\mathbf{8 6 . 4 4}$ \\
Accuracy & & & & & & \\
Overall & $\mathbf{0 . 8 3}$ & $\mathbf{0 . 8 2}$ & $\mathbf{0 . 8 3}$ \\
Kappa & & & & & & \\
\hline
\end{tabular}

PA = Producers' Accuracy, UA = Users' Accuracy

Source: Author's fieldwork, 2018

The user's accuracy for different classes ranged between $50 \%$ and $100 \%$ and the producer's accuracy ranged between 76.47 $\%$ and $91.07 \%$. The results of overall kappa for the three periods 1987, 2007 and 2017 revealed Kappa statistics of 0.83 , 0.82 and 0.83 respectively. The Kappa coefficient for the three periods show that the kappa agreement was virtually in perfect agreement level implying that it can be used.

\section{Trend and rate of change in LULC in Otukpo (1987,2007} and 2017)

Land use and land cover trend in Otukpo (Table 5 and Figure 5) revealed that urban area has been on the increase recording an increase of 5097ha $(156.78 \%)$ in the first period with a $7.84 \%$ annual rate. The second period witnessed dramatic increase to $7127 \mathrm{ha}(85.37 \%)$ at the rate of $8.54 \%$ per year. The overall trend shows an increase of 12224ha (376.01\%) with an annual rate of change of $12.53 \%$. The area of forest declined to the tune of 5945ha $(-17.89 \%)$ in the first period. It further declined by 10548 ha $(-38.65 \%)$ at the rate of $-3.87 \%$ per annum. The overall trend was also negative losing $16493 \mathrm{ha}$
$(-49.63 \%)$ at the rate of $-1.65 \%$. This massive loss of forest land may be partly due to increase in urban area which has taken over areas hitherto occupied by forest and increase in farming area.

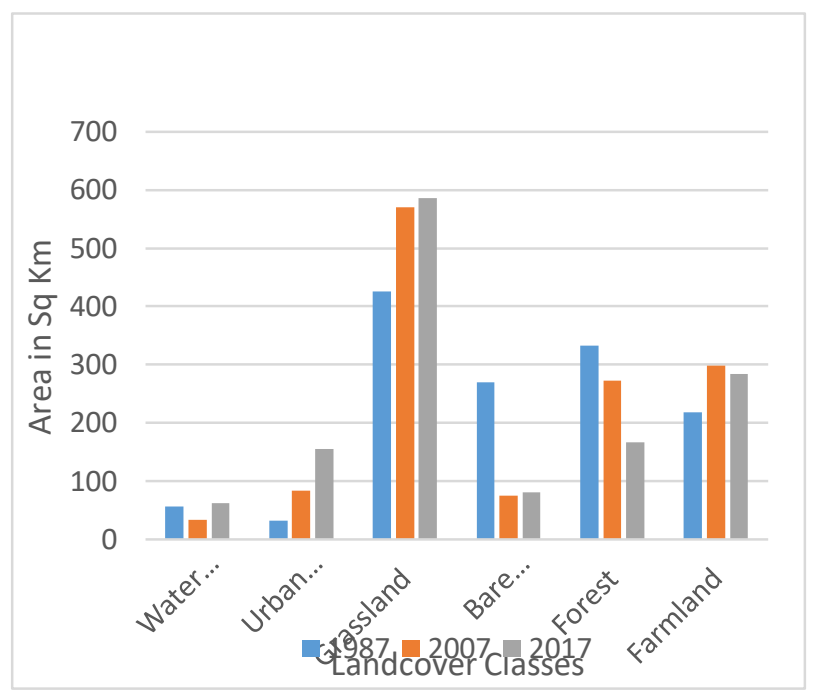

Figure 5: Trend of Land cover changes in Otukpo (1987-2017) Source: Author's fieldwork, 2018

Farmland showed an increase in the first period by 7957 ha $(36.46 \%)$ at the rate of $1.82 \%$. There was, however, a decrease in the second period by $-1432 \mathrm{ha}(-4.81 \%)$ at the rate of $0.48 \%$. The fluctuation may be due to declining food prices which may have discouraged farmers to continue the expansion of land area under cultivation. The overall trend, however showed an increase to $6525 \mathrm{ha}(29.9 \%)$ at the rate of $1 \%$. Grassland witnessed a continuous increase throughout the period, increasing to $14512 \mathrm{ha}(34.1 \%)$ in the first period at the rate of $1.71 \%$ and $1552 \mathrm{ha}(2.72 \%)$ at $0.27 \%$ per annum in the second period. The overall trend shows that 16064 ha $(37.75 \%)$ was gained at the rate of $1.26 \%$. Bare surface and water body showed insignificant fluctuating trend during the period 


\begin{tabular}{|c|c|c|c|c|c|c|c|c|c|}
\hline \multirow{3}{*}{ Water } & \multirow{3}{*}{ 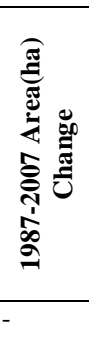 } & \multirow{2}{*}{ 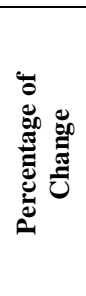 } & \multirow{2}{*}{ 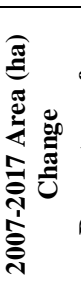 } & \multirow{2}{*}{ 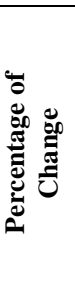 } & \multirow{2}{*}{ 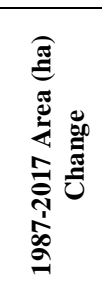 } & \multirow{2}{*}{ 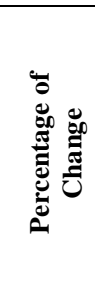 } & \multicolumn{3}{|c|}{$\begin{array}{l}\text { ANNUAL RATE } \\
\text { OF CHANGE } \\
(\%)\end{array}$} \\
\hline & & & & & & & 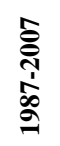 & 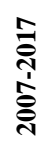 & 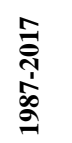 \\
\hline & & 39. & 28 & 82. & & & & 8.2 & \\
\hline Body & 2274 & 95 & 08 & 15 & 534 & 9.38 & 2 & 2 & 0.31 \\
\hline Urban & & 156 & 71 & 85. & 1222 & 376. & 7.8 & 8.5 & 12.5 \\
\hline Area & 5097 & .78 & 27 & 37 & 4 & 01 & 4 & 4 & 3 \\
\hline Grass & 1451 & 34. & 15 & 2.7 & 1606 & 37.7 & 1.7 & 0.2 & \\
\hline land & 2 & 1 & 52 & 2 & 4 & 5 & 1 & 7 & 1.26 \\
\hline Bare & - & - & & & - & - & & & \\
\hline Surfac & 1944 & 71. & 49 & & 1895 & 70.1 & - & 0.6 & \\
\hline e & 7 & 94 & 3 & 6.5 & 4 & 1 & 3.6 & 5 & -2.34 \\
\hline \multirow[t]{4}{*}{ Forest } & & & - & & & & & & \\
\hline & & - & 10 & - & - & - & - & - & \\
\hline & - & 17. & 54 & 38. & 1649 & 49.6 & 0.8 & 3.8 & \\
\hline & 5945 & 89 & 8 & 65 & 3 & 3 & 9 & 7 & -1.65 \\
\hline Farm & & & - & - & & & - & - & \\
\hline \multirow[t]{2}{*}{ land } & & 36. & 14 & 4.8 & & & 1.8 & 0.4 & \\
\hline & 7957 & 46 & 32 & 1 & 6525 & 29.9 & 2 & 8 & 1 \\
\hline
\end{tabular}
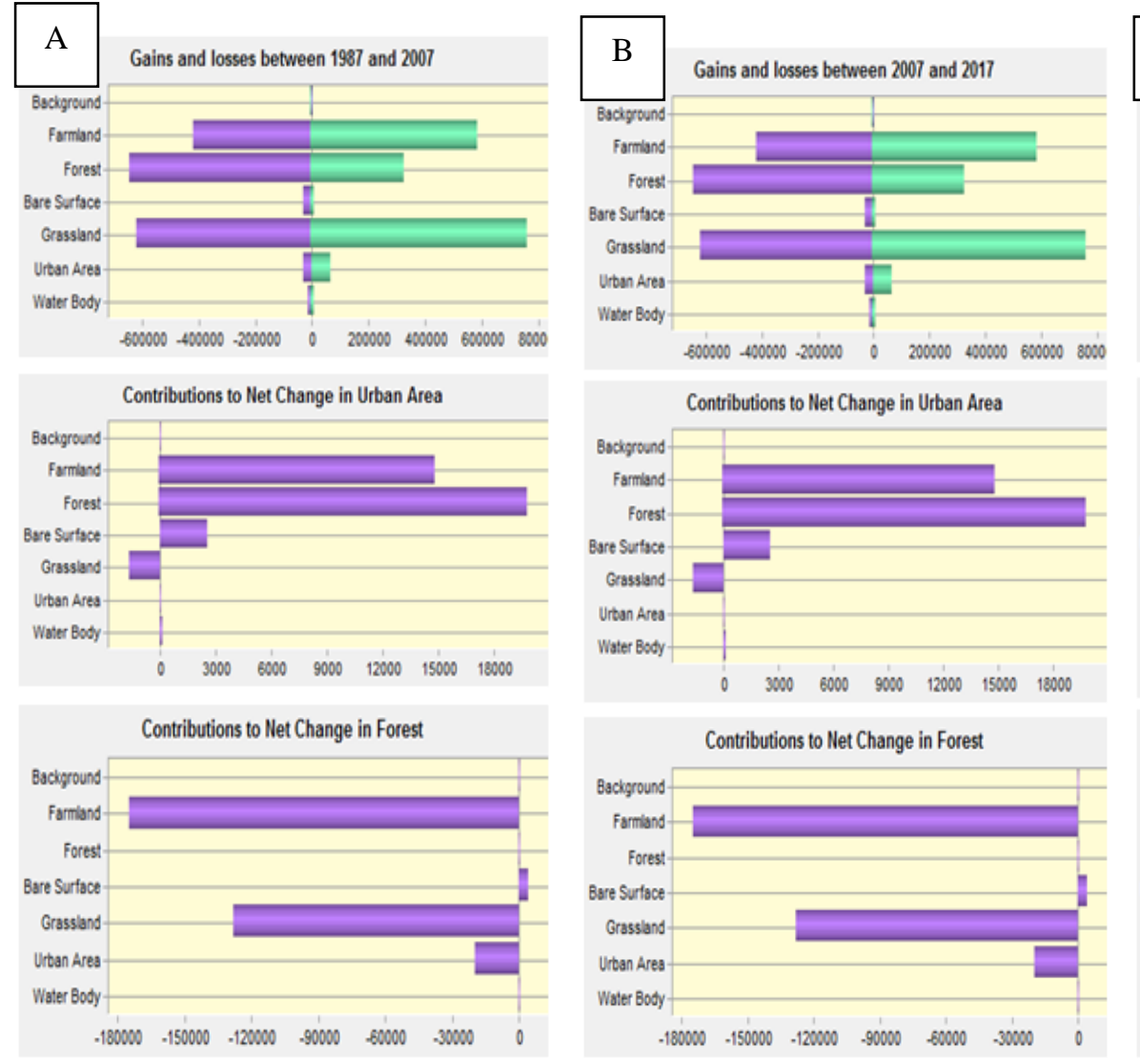

Table 5: Annual Rate of change for Otukpo (1987, 2007 and 2017)

Land change analysis using Land Change Modeler (LCM) The gain and losses graphics in Otukpo (Figure 6a, b and c) show that grassland witnessed the major positive transition followed by urban area. Farmland had a negative transition in the first and second periods but was positive in the overall trend while forest declined throughout during the periods. Contributors to urban expansion came mainly from farmland, grassland and forest during the first two periods but bare surface took over leadership in the overall trend. This was followed by farmland, forest and grassland.

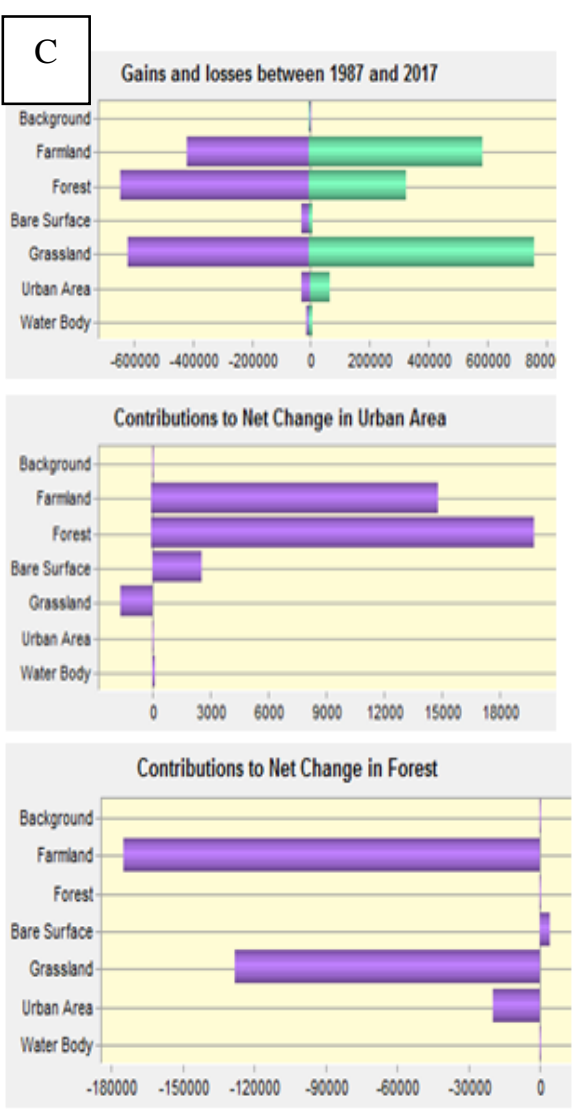




\section{International Journal of Engineering Applied Sciences and Technology, 2020 \\ Vol. 4, Issue 9, ISSN No. 2455-2143, Pages 26-40 \\ Published Online January 2020 in IJEAST (http://www.ijeast.com)}

Figure 6: Gains/losses of LULC categories, contribution to net change in Urban area and Forest (ha) in Otukpo from (A):1987 2007, (B): 2007 -2017 and (C): 1987- 2017.

Source: Author's fieldwork, 2018

\section{Identification of Drivers and their contribution to urban growth}

In order to test the potential power of the drivers (explanatory variables), the LCM's Test and election of site and driver variable module was used. These set of explanatory variables were chosen based on preliminary investigations as well as reviews from relevant academic literatures. Table 6 shows the Cramer's V coefficient for each of the explanatory variables, As can be seen from the table, all the variables namely, likelihood of transition, distance from urban areas, roads, rivers, railways, digital elevation model (DEM), slope and population density selected for transition development were greater than 0.15 , some of them were higher than 0.4 which indicates the selected variables have association with the changes and were used in the process as was shown by Wang and Maduako (2018). It is also evident that likelihood of transition, DEM and population density have values higher that 0.4 , meaning that these three variables are strongly associated with transition and therefore kept in the sub-model structure. Also, the LCM MLP model results reveal that likelihood of transition, distance from urban areas and railways were most important drivers in shaping urban growth as revealed by the influence order.

Table 6: Cramer's V Test values for explanatory variables

\begin{tabular}{lc}
\hline Variable & Cramer's V Value \\
\hline Likelihood & 0.4495 \\
Dist_Urban & 0.3763 \\
Dist_Roads & 0.2904 \\
Dist_Rivers & 0.3200 \\
DEM & 0.5030 \\
Slope & 0.4039 \\
Pop density & 0.4828 \\
Dist_Rails & 0.2349 \\
\hline
\end{tabular}

Source: Author's fieldwork, 2018

\section{Sensitivity Analysis}

Upon completion of the entire process, MLP outputs a number of statistics that provide information regarding the power of the explanatory driver variables as well as the models accuracy in predicting class transitions and persistence. One important aspect of the statistics generated is termed "Forcing Independent Variables to be Constant". After the system has trained on all of the explanatory variables, the system tests for the relative power of explanatory variables by selectively holding the inputs from selected variables constant. Holding the input values for a selected variable constant effectively removes the variability associated with that variable. Using the modified model, the MLP procedure repeats the skill test using the validation data. The difference in skill thus provides information on the power of that variable. This process is repeated for all the driver variables to determine their influence on the skill measure and accuracy of the model.

Three different sensitivity analyses were run. In the first section, a single variable is held constant. This is repeated for all variables. Table 7 shows the sensitivity of holding one variable constant for each of the five selected areas. In the second sensitivity, all variables are held constant (at their mean values) except one

Table 7: Forcing a Single Independent Variable to be Constant

\begin{tabular}{cccc}
\hline Model & $\begin{array}{c}\text { ACC } \\
(\boldsymbol{\%})\end{array}$ & SM & IO \\
\hline With all & 78.05 & 0.7492 & N.A \\
Variables & & & \\
Var.1 constant & 78.02 & 0.7488 & 7 \\
Var.2constant & 75.81 & 0.7235 & 5 \\
Var.3 constant & 77.76 & 0.7458 & 6 \\
Var.4 constant & 71.40 & 0.6732 & 4 \\
Var.5 constant & 78.15 & 0.7503 & $8^{*}$ \\
Var6 constant & 63.21 & 0.5796 & 2 \\
Var.7 constant & 19.91 & 0.0847 & $1 * *$ \\
Var.8 constant & 67.65 & 0.6306 & 3 \\
\hline
\end{tabular}

Key: Acc $=$ Accuracy, $\mathrm{SM}=$ Skill measure, $\mathrm{IO}=$ Influence order, $* *=$ Most Influential, $*=$ Least Influential

Source: Author's fieldwork, 2018

The final test in section 3 is entitled Backwards Stepwise Constant Forcing. Starting with the model developed with all variables, it then holds constant every variable in turn to determine which one has the least effect on model skill. Step 1 thus shows the skill after holding constant the variable that has the lowest negative effect on the skill. If a variable is held constant and the skill does not decrease much, then it suggests that that variable has little value and can be removed (See Table 8). 


\section{International Journal of Engineering Applied Sciences and Technology, 2020 \\ Vol. 4, Issue 9, ISSN No. 2455-2143, Pages 26-40 \\ Published Online January 2020 in IJEAST (http://www.ijeast.com)}

It then tests every possible pair of variables that include that determined in step 1 to figure out which pair, when held constant, have the least effect on the skill. It continues in this manner progressively holding another variable constant until only one variable is left. The backward stepwise analysis is very useful for model development. The backward stepwise MLP result was used in assessing the best model combination of independent variables based on percentage accuracy and skill measure by consecutively eliminating the weakest independent variable one by one.

The results of the backwards stepwise constant forcing in Table 8 shows that the elimination of slope (variable 5) had a higher accuracy of $78.15 \%$ and a 0.7503 skill measure in contrast to $78.05 \%$ accuracy and a 0.7492 skill measure when all the variables were used. These best combinations were then used to project sensitivity of urban built-up area expansion

Table 8: The Result of MLP with backwards stepwise constant forcing

\begin{tabular}{llll}
\hline \multicolumn{1}{c}{ Model } & \multicolumn{1}{c}{$\begin{array}{c}\text { Variables } \\
\text { included }\end{array}$} & \multicolumn{1}{c}{$\begin{array}{c}\text { Accuracy } \\
(\boldsymbol{\%})\end{array}$} & \multicolumn{1}{c}{$\begin{array}{c}\text { Skill } \\
\text { measure }\end{array}$} \\
\hline With all variables & All variables & 78.05 & 0.7492 \\
Step 1: var.[5] constant & {$[1,2,3,4,6,7,8]$} & 78.15 & 0.7503 \\
Step 2: var.[5,1] constant & {$[2,3,4,6,7,8]$} & 77.98 & 0.7483 \\
Step 3: var.[5,1,3] constant & {$[2,4,6,7,8]$} & 77.34 & 0.7411 \\
Step 4: var.[5,1,3,2] constant & {$[4,6,7,8]$} & 73.07 & 0.6922 \\
Step 5: var.[5,1,3,2,4] constant & {$[6,7,8]$} & 65.95 & 0.6108 \\
Step 6: var.[5,1,3,2,4,6] constant & {$[7,8]$} & 63.95 & 0.5880 \\
Step 7: $\quad$ var.[5,1,3,2,4,6,8] & {$[7]$} & 49.97 & 0.4283 \\
constant & & & \\
\hline Source: Author's fieldw0rk & 2018 & &
\end{tabular}

Source: Author's fieldwork, 2018

Table 9 presents list of all independent variables used in the modelling process with their corresponding numbers. Distance from urban area was assigned number 1, distance from roads, number 2, through to the last variable distance from railways with number 8 as can be seen in Table 9

Table 9: List of independent variables

\begin{tabular}{ll}
\hline Variable Code & Name of Variable \\
\hline Independent variable 1 & Distance from urban area in 1987 \\
Independent variable 2 & Distance from roads \\
Independent variable 3 & Distance from rivers \\
Independent variable 4 & Digital elevation model \\
Independent variable 5 & Slope \\
Independent variable 6 & Population density \\
Independent variable 7 & Evidence likelihood of transition \\
Independent variable 8 & Distance from railways \\
\hline
\end{tabular}

Source: Author's fieldwork, 2018

\section{Transition Potential Modelling using MLP}

After selecting the predictor variables, all the transitions were then modeled in one transition sub-model called urban area, as they had the same driving forces, with the aim of producing the transition maps. As earlier stated, MLP was used in modelling the transitions and it generated transition potential maps for each of the evaluated transition sub-models. The results of the MLP transition modelling is presented in Figure 7. There were four transitions to urban area. These were transitions from grassland, bare surface, forest and farmland to urban area as can be seen in figure 7. These transition potential maps generated from MLP modelling were then used in Markov Chain model for determining the amount of change to be expected for each transition and for predicting of future scenarios.

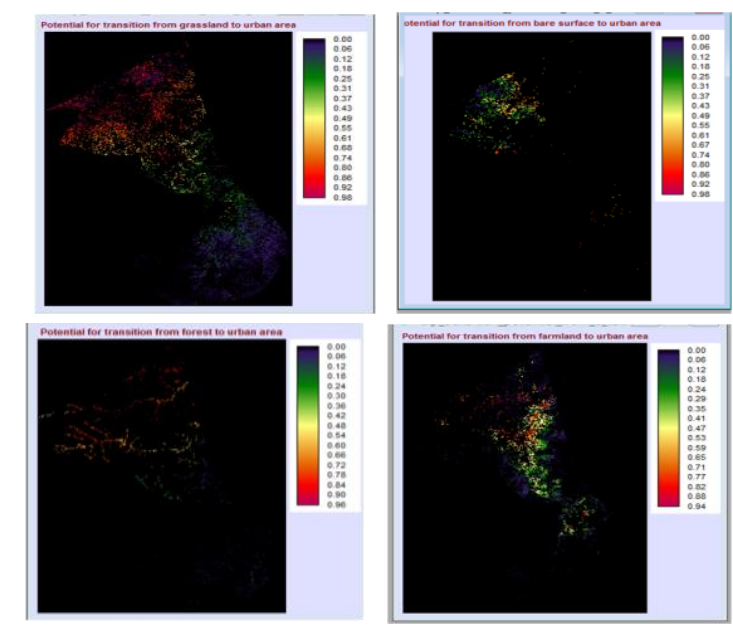

Figure 7: Transition potential maps for Otukpo

Source: Author's fieldwork, 2018

\section{Model Predictions and Validations}

Results from Markov chain model predictions are based on a transition probability matrix of land use and land cover changes from 1987 to 2007 and changes in the past. This formed the basis for projection to 2017. Figures 8 showed the actual and predicted land cover maps of Otukpo for the year 2017 which showed noticeable differences. This had been expected as the historical change processes from 1987 to 2007 cannot be the same as from 2007 to 2017 in Markov chain analysis. Again, the driving variables are bound to vary during the period thereby affecting the prediction results. The validation (Figure 8) shows that the predicted urban area was slightly less than that in the actual map while forest were overestimated 


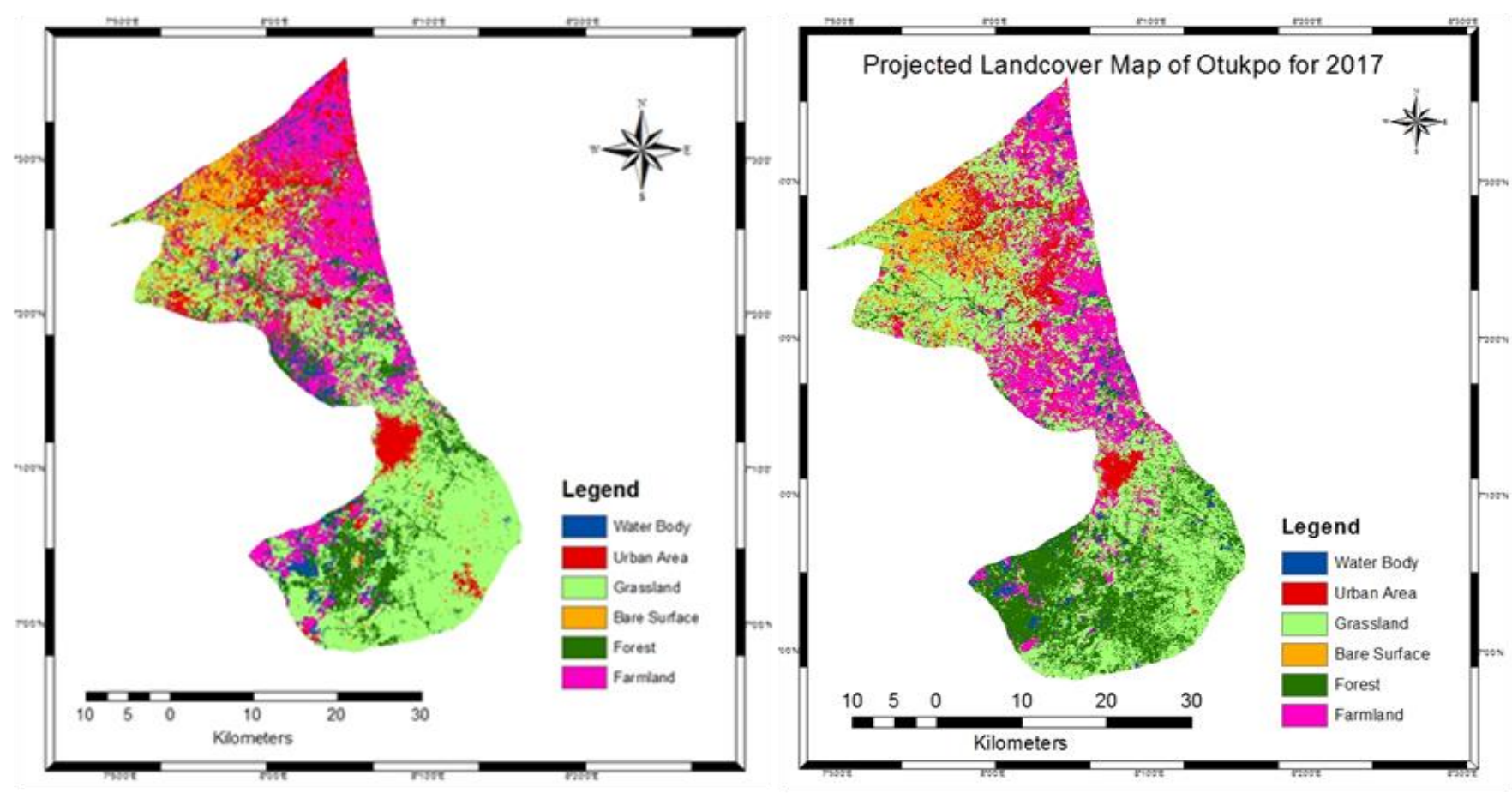

Figure 8: Land cover maps of Otukpo for 2017 (Actual, left and predicted, right) Source: Author's fieldwork, 2018

In contrast to the hard prediction, in the soft prediction map most of the areas that had actual change in 2017 are considered to be vulnerable. In order to assess the extent to which this model was able to predict future land use and land cover through soft prediction, the Relative Operating Characteristic (ROC) in Idrisi Selva was used. The ROC statistic reveals how well a continuous surface predicts the locations given a distribution of a Boolean variable. In this case the soft prediction was used as the continuous surface to evaluate against the real change between 2007 and 2017. The result of the ROC statistic reveal an Area Under the Curve (AUC) value of 0.817 which indicate strong value, indicating the soft prediction were very good. Spatial modelling and simulation are not about creating models that can perfectly predict future states. It is and will always be impossible. But efforts should be made to bring us as close to this state as possible. In this context a created model can be considered a successful modelling tool.

Modelling and prediction of the pattern of urban growth for 2030

After model validation, both hard and soft predictions were performed for the year 2030 so as to map possible transitions from other land use and land cover categories to urban area. The prediction was restricted to short-term as they are more accurate than long term predictions (Alba, 2011; Araya, 2009). Figure 9 shows the predicted land cover map in 2030 complemented by table 10 . The resulting 2030 prediction indicate that there will be significant changes in the future.

The dominant land cover category will also be grassland occupying 65986ha $(49.43 \%)$, followed by farmland with 25787 ha $(19.32 \%)$. Urban area is projected to occupy 16819 ha $(12.6 \%)$, forest area $14660 \mathrm{ha}(10.98 \%)$, bare surface $6830 \mathrm{ha}$ $(5.12 \%)$ and water body will occupy 3409 ha $(2.55 \%)$.

\begin{tabular}{|c|c|c|c|c|c|c|}
\hline & & in & LULC & in & Chang & \\
\hline $\begin{array}{l}\text { Classe } \\
\text { s }\end{array}$ & $\begin{array}{l}\text { Area } \\
(\mathbf{H a})\end{array}$ & $\begin{array}{l}\text { Area } \\
(\%)\end{array}$ & $\begin{array}{l}\text { Area } \\
(\mathbf{H a})\end{array}$ & $\begin{array}{l}\text { Area } \\
(\%)\end{array}$ & $\begin{array}{l}\text { Area } \\
\text { (Ha) }\end{array}$ & $\begin{array}{l}\text { Rate } \\
\%\end{array}$ \\
\hline Water & 6226 & 4.66 & 3409 & 2.55 & - & -2.11 \\
\hline Body & & & & & 2817 & \\
\hline Urban & 1547 & 11.5 & 1681 & 12.6 & 1344 & 1.01 \\
\hline Area & 5 & 9 & 9 & 0 & & \\
\hline Grass & 5862 & 43.9 & 6598 & 49.4 & & 5.51 \\
\hline land & 3 & 2 & 6 & 3 & 7363 & \\
\hline Bare & 8080 & 6.05 & 6830 & 5.12 & - & -0.93 \\
\hline Surface & & & & & 1250 & \\
\hline \multirow[t]{2}{*}{ Forest } & 1674 & 12.5 & 1466 & 10.9 & - & -1.56 \\
\hline & 1 & 4 & 0 & 8 & 2081 & \\
\hline Farmla & 2834 & 21.2 & 2578 & 19.3 & - & -1.92 \\
\hline nd & 6 & 4 & 7 & 2 & 2559 & \\
\hline Total & $\begin{array}{l}1334 \\
91\end{array}$ & 100 & $\begin{array}{l}1334 \\
91\end{array}$ & 100 & & \\
\hline
\end{tabular}




\section{International Journal of Engineering Applied Sciences and Technology, 2020 \\ Vol. 4, Issue 9, ISSN No. 2455-2143, Pages 26-40 \\ Published Online January 2020 in IJEAST (http://www.ijeast.com)}

Table 10: Projected land cover statistics of Otukpo for 2030 Source: Author's fieldwork, 2018

The result of land cover prediction for Otukpo (Table 11 and Figure 9) shows that between 2017 and 2030, only grassland and urban area were estimated to increase by $5.51 \%$ and $1.01 \%$ from $43.92 \%$ and $11.59 \%$ in 2017 to $49.93 \%$ and $12.60 \%$ in 2030 . The urban area is predicted to stretch from the centre of the region eastward. This pattern of growth is at variance with the prediction in many urban areas like Makurdi and Gboko where urban growth is accompanied by a corresponding growth in farmland.

Table 11: Changed areas between LULC in 2017 and LULC in 2030 for Otukpo

\begin{tabular}{lll}
\hline Land cover Class & Area (Ha) & Area (\%) \\
\hline Water Body & 3409 & 2.55 \\
Urban Area & 16819 & 12.60 \\
Grass land & 65986 & 49.43 \\
Bare Surface & 6830 & 5.12 \\
Forest & 14660 & 10.98 \\
Farm land & 25787 & 19.32 \\
Total & $\mathbf{1 3 3 4 9 1}$ & $\mathbf{1 0 0}$ \\
\hline
\end{tabular}

Source: Author's fieldwork, 2018
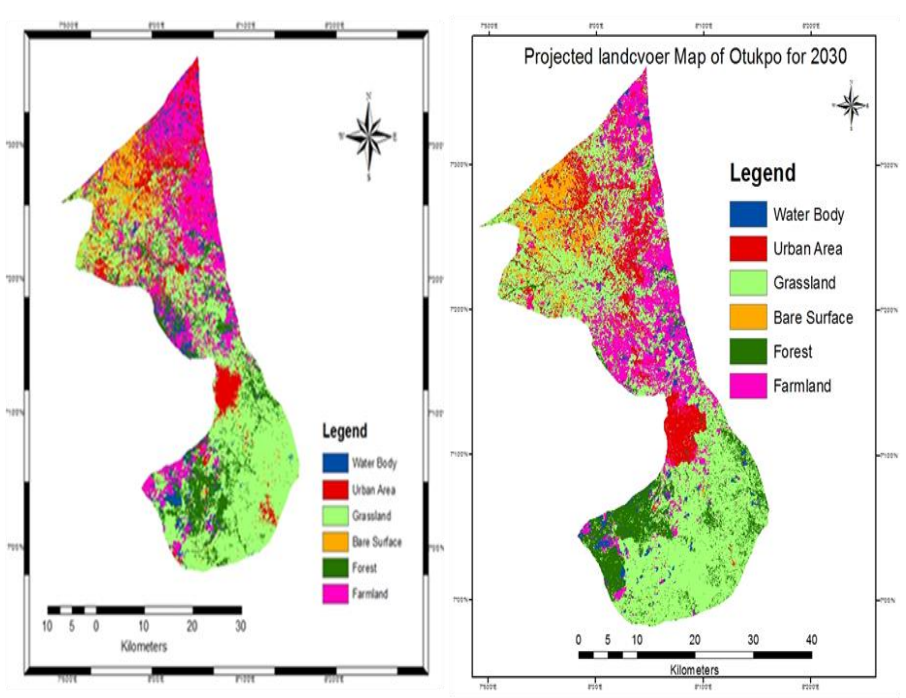

Figure 9: Land cover maps of Otukpo (2017 left, and 2030 projected, right)

Source: Author's fieldwork, 2018
This prediction agrees with work in Semarang City in Java, Indonesia by Hadi et al, (2016). The findings also showed that the farmland will decrease from about 28346ha in 2017 to 25787 ha by 2030 . This can be explained by the changing nature of activities from predominantly agriculture to secondary and tertiary activities in the area. This trend in land cover change is similar to that of Wudil town in Kano city in Nigeria, where the cultivated land is projected to decrease by about $2.38 \%$ over a period of 14 years as discovered by Ismail and Abubakar (2015). The prediction also reveals that farmland, forest and bare surface will decline during the period by $-1.92 \%,-1.56 \%$ and $-0.93 \%$ respectively resulting in 25787ha, 14660ha and 6830ha in 2030. The major reason for the conversion is as a result of high demand for land and it would be easy to convert these land cover types due to fewer or no restrictions. These land use types facilitate urbanization as these classes have more potential to change to urban areas. Soft Prediction

The soft prediction output is made up of maps that show the probability of change for a given set of transitions. The soft output represents a continuous mapping of vulnerability to change for selected set of transitions. This prediction identified the extent to which the land area has the susceptibility to be altered. The soft prediction output detected the areas with varying degrees of vulnerability instead of identifying what and how much of land cover categories would be changed. From the modelled output for Otukpo shows that the north has higher vulnerability values compared to the other areas.

\section{Implications of the observed impacts}

Urban growth has continued to be a threat to the existence of forest for a long time due to deforestation. The depleting forest resources is a threat to biodiversity The results indicated that urban growth is one of the major drivers of land use and land cover changes in Otukpo area.

Agricultural expansion is also affected by urban expansion as areas previously under cultivation are converted to urban areas. This has the effect of reducing areas under cultivation especially at the fringes where there exist barriers to prevent further expansion of these agricultural areas. This has a tendency of reducing farm output if intensive practices are not adopted. Where there are no barriers, there is the tendency for cultivated areas to expand further to accommodate the loss to urban areas thereby causing more deforestation. Implications of urban expansion include loss of open space, pressure on limited infrastructure, overcrowding, traffic congestion and poor standard of living.

\section{Recommendations}

Based on the nature and rate of change of various land use and land cover types identified in the study area especially from 1987 to 2017 and the modelled results for 2030, the following recommendations are made: 


\section{International Journal of Engineering Applied Sciences and Technology, 2020 \\ Vol. 4, Issue 9, ISSN No. 2455-2143, Pages 26-40 \\ Published Online January 2020 in IJEAST (http://www.ijeast.com)}

- As a result of the increasing urban expansion at the cost of farmland and the likelihood of its continuation in the future, food insecurity and environmental disequilibrium are most likely. Developing and implementing proper urban plans for the protection of farmlands is urgently required. Proper urban planning to ensure the protection of farmlands is crucial to create resilient urban environment and sustainable development.

- Government should evolve a policy that will prioritise the provision of infrastructural facilities and social amenities to cater for the envisaged urban growth especially in Otukpo.

- The populace should be sensitized through enlightenment campaigns on the need to embrace community and urban forestry so as not destroy existing forest but conserve them for the benefit of the environment and avoid the consequences of deforestation.

- Tree planting should be encouraged by all concerned to cushion the effect of the deforestation occasioned by rapid urban growth in the state.

- A holistic approach needs to be adopted for increasing the vegetal cover in the urban and rural areas. This can be achieved through various means such as planting of more trees, especially on sidewalks in the residential areas and on public/private properties. This also requires community awareness on the adverse impact of current inefficient urban form and the importance of establishing environment friendly cities.

- Most importantly, the planning and decision-making authorities must integrate new technologies, such as remote sensing and GIS into their decision making processes. Using remote sensing data and information to understand the dynamics of the urban environment may contribute to better urban policy and management.

- Urban growth monitoring and management involve different governmental and non-governmental agencies. Therefore, institutional coordination among those various stakeholders at different levels is required for sustainable development and environmental management.

\section{CONCLUSION}

It is well known that the future is uncertain. But having the ability to factor in specific areas within the uncertainty grants key insights that can prove to be very important in taking vital decisions when considering the future. As the urban areas of Otukpo continue to expand, understanding the current patterns of urban growth and land use and their impact and predicting the possible future patterns of growth of the urban areas will empower the government other stakeholders and policy makers by providing them with information and support that will prove to be essential for future planning and development decisions.

This study reveals that the combination of GIS, remote sensing, and modelling offers a potent tool for observing spatio-temporal LULC change, plus modelling complex interactions between man and nature. The outcome of the LULC change study showed the main change paths in Otukpo particularly the expansion of urban areas is at the detriment of farmland, grassland and forest. This research concludes that the expansion of urban areas occurred at the expense of farmlands, grassland and forest land which implies that the state will experience serious crises of managing the urban growth if adequate planning measures are not put in place. Therefore, focus on urban planning is essential to control the expansion of urban areas and make provision for infrastructural facilities in areas that are predicted to be transformed to urban centres thereby minimizing the negative impacts of urban expansion in the area.

\section{Acknowledgement}

The authors wish to express appreciation to United States Geological Surveys (USGS), Global Land Cover Facility (GLCF) and GloVis for providing the platform through which the Landsat Imageries were downloaded.

\section{REFERENCE}

[1] Abah, R. C. (2014). Rural perception to the effects of climate change in Otukpo, Nigeria.Journal of Agriculture and Environment for International Development, 108(2), (pp 153-166). https://doi.org/10.12895/jaeid.20142.217

[2] Alba, H. de. (2011). Deforestation in the Kayabi Indigenous Territory: Simulating andPredicting Land Use and Land Cover Change in the Brazilian Amazon. Unpublished Master Thesis Birkbeck College, University of London.

[3] Anderson, J. R., Hardy, E. E., Roach, J. T., \& Witmer, R. E. (1976). A Land Use and LandCover Classification System for Use with Remote Sensor Data (Fourth). Washington: United States Department of the Interior.

[4] Araya, Y. H. (2009). Urban Land Use Change Analysis and Modeling: A Case StudyofSetúbal And Sesimbra, Portugal. Unpublished Master Thesis University Jaume I.

[5] Bloch, R., Monroy, J., \& Fox, S. (2015). Urbanisation and Urban Expansion In Nigeria.

[6] BNSG. (2017). In the Spotlight: Historical Background. Retrieved October 24, 2017, from https://benuestate.gov.ng/historical-background 


\section{International Journal of Engineering Applied Sciences and Technology, 2020 \\ Vol. 4, Issue 9, ISSN No. 2455-2143, Pages 26-40 \\ Published Online January 2020 in IJEAST (http://www.ijeast.com)}

[7] Borana, S. L., \& Yadav, S. K. (2017). Prediction of Land Cover Changes of JodhpurCityUsing Cellular Automata Markov Modelling Techniques. International Journal of Engineering Science and Computing, 7(11), (pp 15402-15406).

[8] Congedo, L., \& Munafò, M. (2012). Development of a Methodology for Land CoverClassification in Dar es Salaam using Landsat Imagery. Rome.

[9] Debnath, R., \& Amin, A. T. M. N. (2015). A geographic information system-based logicalurban growth model for predicting spatial growth of an urban area. Environment and Planning B: Planning and Design, 43(3),( pp 580-597). https://doi.org/10.1177/ 0265813515618565

[10] Hadi, F., Thapa, R. B., Helmi, M., Hazarika, M. K., Madawalagama, S., \& Deshapriya, L.N. (2016). Urban Growth and Land Use / Land Cover Modeling in Semarang, Central Java, Indonesia. In ColomboSrilanka (Ed.), Asian Conference on Remote Sensing 2016 (pp. 1-10). ACRS. Retrieved from http://www.geoinfo.ait.asia/downloads/publications /2016-hadi.pdf

[11] Halima, C. I., \& Edoja, M. S. (2016). Exploring the relationship between farming practicesand vegetation dynamics in Benue State, Nigeria. African Journal of Geography and Regional Planning, 3(1), (pp 218-225). Retrieved from http://wsrjournals.org/ journal/wjas

[12] Huang, S. L., Wang, S. H., \& Budd, W. W. (2009). Sprawl in Taipei's peri-urban zone:Responses to spatial planning and implications for adapting global environmental change. Landscape and Urban Planning, 90,( pp 20-32). https://doi.org/10.1016/j. landurbplan. 2008.10.010

[13] Hula, M. A. (2014). Population Dynamics and Vegetation Change in Benue State, Nigeria.Journal of Environmental Issues and Agriculture in Developing Countries, 2(1) (pp53-69). https://doi.org/10. 13140/2.1.4805.1847

[14] Ismail, M., \& Abubakar, S. (2015). Full Length Research Paper Geospatial Projection ofLanduse / Landcover Change in Wudil Town of Kano State ,. International Journal of Scientific Research in Environmental Sciences, 3(11), (pp 0401-0410).

[15] Jain, R. K., Jain, K., \& Ali, S. R. (2017). Modeling Urban Land Cover Growth DynamicsBased on Land Change Modeler ( LCM ) Using Remote Sensing: A Case Study of Gurgaon, India. Advances in Computational
Sciences and Technology, 10(10), (pp 2947-2961).

[16] NASA. (2011). Landsat 7 science data users handbook. National Aeronautics and SpaceAdministration Landsat. Retrieved from http://glovis.usgs. gov/\%0Ahttp://edcsns17 .cr.usgs. gov/EarthExplorer/

[17] NBS. (2012). Annual Abstract of Statistics , 2012. Abuja: National Bureau of Statistics.

[18] Richards, J. A., \& Jia, X. (2006). Remote Sensing Digital Image Analysis. New York:Springer.

[19] Saifullah, K., Barus, B., \& Rustiadi, E. (2017). Spatial modelling of land use / cover change ( LUCC ) in South Tangerang City, Banten. IOP Conference Series: Earth and Environmental Science, 54(1), (pp 112). https://doi.org/10.1088/1742-6596/755/1/011001

[20] Ujoh, F., Dlama, K. I., \& Oluseyi, I. O. (2011). Urban expansion and vegetal cover loss inand around Nigeria ' s Federal Capital City. Journal of Ecology and the Natural Environment, 3(1), (pp 1-10).

[21] UN. (2014). World Urbanization Prospects: The 2014 Revision, Highlights. Department of Economic and Social Affairs ST/ESA/SER.A/352 United Nations.

[22] Wang, J., \& Maduako, I. N. (2018). Spatio-temporal urban growth dynamics of LagosMetropolitan Region of Nigeria based on Hybrid methods for LULC modeling and prediction Spatio-temporal urban growth dynamics of Lagos Metropolitan Region of. European Journal of Remote Sensing, 51(1), (pp.251-265). https://doi.org/10. 1080/22797254.2017.1419831 